\title{
Role of Temperament, Personality Traits and Onset Age of Smoking in Predicting Opiate Dependence
}

\author{
Bahareh Amirabadi, ${ }^{1, *}$ Mohammad Nikbakht,, Mostafa Nokani, ${ }^{2}$ Neda Alibeygi, and Hadi \\ Safari ${ }^{4}$ \\ ${ }^{1}$ Department of Clinical Psychology, Faculty of Medical Sciences, Shahid Beheshti University of Medical Sciences, Tehran, IR Iran \\ ${ }_{2}^{2}$ Department of Clinical Psychology, Faculty of Medical Sciences, Arak University of Medical Sciences, Arak, IR Iran \\ ${ }^{3}$ Department of Psychiatry, Faculty of Psychiatry, University of Rehabilitation and Welfare Sciences, Tehran, IR Iran \\ ${ }^{4}$ Department of psychology, Faculty of psychology, Semnan University, Semnan, IR Iran \\ ${ }^{*}$ Corresponding author: Bahareh Amirabadi, Department of Clinical Psychology, Faculty of Medical Sciences, Shahid Beheshti University of Medical Sciences, Tehran, IR Iran. Tel: \\ +98-9127852137, E-mail: bahareh_amirabadi@yahoo.com
}

Received 2014 October 30; Revised 2015 February 5; Accepted 2015 February 9.

\begin{abstract}
Background: According to drug gateway theory, smoking cigarettes, especially, low onset age of smoking, is one of the risk factors for future use.

Objectives: The present study aimed to compare nicotine and opiate addicts to identify the differences in personality traits and onset age of smoking in the two groups that cause some individuals to appeal to other substances after starting to use cigarettes.

Patients and Methods:Two groups of opiate and nicotine addicts were randomly selected. Revised version of the Cloninger temperament inventory questionnaire, the Fagrastrom nicotine dependence and the Maudsley addiction profile were used. ANOVA and logistic regression were applied for data analysis.

Results: Opiate addicts had higher scores in novelty seeking dimension and lower scores in cooperativeness compared to nicotine addicts. The onset age of smoking cigarette in opiate addicts was lower than nicotine addicts.

Conclusions: Low onset age of smoking cigarettes, high novelty seeking and low cooperativeness in opiate dependents are among the important personality traits in future use of drugs that can predict the subsequent onset of using opiate drugs.
\end{abstract}

Keywords: Temperament, Character, Nicotine, Substance Dependence

\section{Background}

Drug abuse or dependence is derived from a set of factors including social and family issues, availability, and individual's disposition $(1,2)$. Personality is another factor that may play an important role in preparation, acceleration, or maintenance of drug abuse or dependence behaviors. Personality disorders are highly observed among drug abusers both in clinical population $(3,4)$ and non-clinical population (5-7). Moreover, personality is a significant clinical feature that also affects smoking patterns and may influence the nicotine withdrawal syndrome expressions (8). The influential role of a number of personality traits in drug abuse and dependence is proved. Transferring from regular smoking stage to dependence stage depends on factors such as personality disorders or psychiatric diseases (9). Numerous studies recognized that in addition to personality traits, onset age of smoking is also one of the important predictor variables in future dependence to other illegal substances. Many studies concluded that smoking is a risk factor among teenagers to be addicted to other drugs. Frequent use of cigarettes is an introduction to consumption of illegal drugs. Kandel et al. reported a significant relation between smoking cigarettes and use of other illegal drugs among high school students; the use of illegal drugs in smokers who smoked daily was much higher than non-smokers (10). Findings of several studies indicate that $98 \%$ of hashish users, before starting to use hashish, had used to smoke tobacco, and onset age of using hashish in these individuals was lower than the starting age of hashish consumption (11). Individual traits such as genetic preparedness and personality traits, or environmental factors such as drug availability or peer influence, and lower age of smoking onset are among the strong predicting factors in future dependence that can explain the sequence of starting from one drug to another (12).

\section{Objectives}

The current research aimed to investigate the personality traits and onset age of smoking cigarettes as predicting variables in future use of illegal drugs.

Copyright (C) 2015, Zahedan University of Medical Sciences. This is an open-access article distributed under the terms of the Creative Commons Attribution-NonCommercial 4.0 International License (http://creativecommons.org/licenses/by-nc/4.0/) which permits copy and redistribute the material just in noncommercial usages, provided the original work is properly cited. 
Amirabadi B et al.

\section{Patients and Methods}

The present research was a causal-comparative study performed on 45 male nicotine addicts and 45 male opiate dependent individuals. Using random sampling, the researchers attended a smoking cession center in Qazvin, Iran, and then, individuals who had been recognized to be nicotine dependent, according to the Fagstrome questionnaire and diagnosis of the physician in that center, were selected. These individuals had passed six months of their treatments in this center and did not display smoking withdrawal symptoms. The inclusion criteria were lack of severe psychiatric disorders and non-dependence on different types of drugs. Then, the Cloninger temperament and character questionnaire was administered. Also, the onset age of smoking in these individuals was recorded. Additionally, the researchers randomly attended four treatment centers for drug abuse and dependence in Qazvin and individuals recognized to be drug dependents, according to the Maudsley addiction profile and physicians' diagnosis, were selected. These individuals had passed six months of their treatments and they did not display any drug withdrawal symptoms. The inclusion criteria were smoking, lack of severe psychiatric disorders and non-dependence on different types of drugs. Then, the Cloninger temperament and character questionnaire was administered. Moreover, the onset age of smoking cigarettes in these individuals was recorded. At the beginning of the sampling process, in both groups, individuals who were qualified to participate in the groups were given structured interview. Data were analyzed by SPSS software version 16, using ANOVA and multivariate regression tests.

\subsection{The Cloninger Temperament and Character Inventory}

This 250-item questionnaire includes two dimensions of temperament and character. Temperament includes novelty seeking, harm avoidance, reward dependence, and persistence; and character dimension includes selfdirectedness, cooperativeness, and self-transcendence. The internal reliability of this test is reported $0.80-0.89$ (13). The internal reliability of the revised version, translated by Ayati, Chemikar, and Pourshahbaz is 0.82 (14).

\subsection{The Fagerstrom Nicotine Dependence Ques- tionnaire}

This 60-item questionnaire was applied to find the therapeutic results including four areas:1) drug use, 2) physical health, 3) mental health, and 4) high-risk behaviors. The internal correlation coefficient of this questionnaire is higher than 0.75 and its reliability is reported $0.65-0.74$ (15).

\section{Results}

Both groups were homogeneous in terms of their variables. In the education variable, a significant inter-group difference was observed. The opiate-dependent group was lower than nicotine-dependent group. Age-related data is presented in Table 1 .

Table 2 indicates the statistics related to the comparison of seven personality dimensions between the two groups. As indicated, there was a significant difference between the two groups. It means that novelty seeking in dependents of opiate drugs was higher than those of dependents of nicotine $(P=0.000)$. Also, there was a significant difference in cooperativeness dimension between these two groups. Cooperativeness of opiate addicts was lower than that of nicotine addicts $(\mathrm{P}=0.000)$.

The obtained results indicated that the mean of smoking onset in dependents of opiate drugs was lower than that of the dependents of nicotine. Table 3 demonstrates the t-test results for the variable of onset age of smoking.

The obtained results indicated the significance of logistic regression in variables of onset age of smoking cigarettes, education, and personality traits in predicting the dependence on opiate substances (Table 4).

According to Table 4, low onset age of smoking cigarettes, lower education level, along with lower scores in self-directedness and cooperativeness traits, predict future dependence on opiate substances.

Table 1. Statistical Indicator of Subjects' Age

\begin{tabular}{lc}
\hline Group & Age Statistical Indicator $^{\mathrm{a}}$ \\
\hline Opiate addicts & $35.97(7.24)$ \\
Nicotine addicts & $39.02(6.22)$ \\
\hline Ordinary population & $37.06(8.31)$ \\
\hline
\end{tabular}

${ }^{\mathrm{a}}$ Values are presented as mean (SD).

\begin{tabular}{|c|c|c|c|c|}
\hline \multirow[t]{2}{*}{ Variable } & \multicolumn{2}{|c|}{ Group $^{\mathrm{a}}$} & \multirow[t]{2}{*}{$\mathbf{F}$} & \multirow[t]{2}{*}{$\mathbf{P}$} \\
\hline & Opiate Dependence & Nicotine Dependence & & \\
\hline Novelty seeking & $86.08(8.51)$ & $79.33(7.17)$ & 0.00 & 0.00 \\
\hline Harm avoidance & $82.15(6.11)$ & $79.97(6.53)$ & 0.28 & 0.16 \\
\hline Reward dependence & $75.55(6.47)$ & $76.13(7.82)$ & 0.48 & 0.36 \\
\hline Persistence & $1.04(10.43)$ & $1.07(11.16)$ & 0.52 & 0.26 \\
\hline Self-directedness & $91.42(8.39)$ & $89.73(12.24)$ & 0.54 & 0.42 \\
\hline Cooperativeness & $87.46(6.52)$ & $97.06(6.48)$ & 0.00 & 0.00 \\
\hline Self-transcendence & $74.33(8.91)$ & $76.88(8.69)$ & 0.37 & 0.19 \\
\hline
\end{tabular}

${ }^{\mathrm{a}}$ Values are presented as mean (SD). 
Amirabadi B et al.

Table 3. Comparison of the Two Groups in Terms of Onset Age of Smoking Cigarettes

\begin{tabular}{lccccc}
\hline Variable & Opiate Drugs $^{\mathrm{a}}$ & Cigarette $^{\mathrm{a}}$ & df & t & P \\
\hline Onset age of smoking cigarettes & $17.68(3.80)$ & $24.88(4.31)$ & 86.31 & -8.40 & 0.00 \\
\hline${ }^{\mathrm{a}}$ Values are presented as mean (SD). & & & &
\end{tabular}

\begin{tabular}{lcccc}
\hline Table 4. Logistic Regression for Predicting Opiate Dependence & & & & \\
\hline Personality traits & B & SD & Level & Exp (B) \\
\hline Age & 0.18 & 0.10 & 0.07 & 1.20 \\
Marital status & -0.09 & 1.24 & 0.93 & 0.90 \\
\hline Education level & 1.12 & 0.41 & 0.00 & 3.06 \\
\hline Onset age of smoking cigarettes & 0.42 & 0.14 & 0.00 & 1.52 \\
\hline Novelty seeking & -0.24 & 0.15 & 0.11 & 0.78 \\
Harm avoidance & -0.01 & 0.11 & 0.88 & 0.98 \\
\hline Reward dependence & -0.02 & 0.08 & 0.79 & 0.97 \\
Persistence & 0.00 & 0.09 & 0.99 & 1.00 \\
\hline Self-directedness & 0.13 & 0.07 & .04 & 0.87 \\
Cooperativeness & 0.44 & 018 & .01 & 1.55 \\
Self-transcendence & -0.01 & 0.09 & .89 & 0.98 \\
\hline
\end{tabular}

\section{Discussion}

The obtained results indicated a significance difference between the two groups in the dimensions of novelty seeking and cooperativeness. Novelty seeking reflected a hereditary orientation in onset or activation of novelty seeking response, approach to reward cues, active avoidance of conditioned punishment cues, and unconditioned punishment escape. This dimension is observed as an exploratory activity in responding to novelty, impulsivity, exaggeration in approaching to reward cues, indulgence and disorder, fatigue and quick fed up, and active avoidance of failure. Different neural moderators are involved in temperament dimensions. The neural moderator of novelty seeking is dopamine which is an incentive neural moderator. Behavioral responses sent after novelty seeking includes exploratory pursuit, voracity, active avoidance, and escape. Therefore, opiate addicts have traits such as indulgence in approach to reward cues, impulsivity, novelty seeking and pursuit of reward cues that distinguish them from the other groups. Many of these traits cause an individual to go towards activities in which the person looks for reward cues, seeks novelty, and acts impulsively. Impulsivity is one of the key traits of this dimension. In other researches, also, novelty seeking dimension in drug addicts was higher than that of the ordinary population, and in some studies, it was higher than that of the alcohol addicts $(16,17)$.

Thus, findings of the current research can be explained as follows: opiate dependent individuals have traits such as indulgence in approach to reward cues, impulsivity, novelty seeking, and pursuit of reward cues that distinguishes them from the other groups. Drug, itself, is a very strong incentive reward and affects the reward system of the brain. Drug dependent individuals use drugs to supply the dopamine for their limbic system which is the reward system of brain, (18). Also, these people display behaviors such as exploratory pursuits of drugs, active avoidance of withdrawal cues (including pain, and unpleasant physical and mental states) and voracity. Voracity is one of the important factors in drug abuse, staying in withdrawal, and failure to return. Voracity is high in drug addicts and high voracity has a negative correlation with successful withdrawal. This dimension of personality traits in the current research was compatible with many of the previous studies in this area such as results gained by Ball et al. (19), Gabel et al. (20), Le Bon et al. (8), Evren et al. (21), and Herrero et al. (22).

Also, cooperativeness dimension in opiate dependent inpatients was significantly lower than those of the other groups. Individuals with higher degrees of this dimension consider themselves as an inseparable member of the human society and are, generally, sympathetic, patient, compassionate, merciful, and supportive, and adhere to the principles and rules. People with low cooperativeness are self-attracted, impatient and intolerant, critical, avenger, and opportunistic. These individuals do not usually assist others, and in every situation, first think about themselves. Also, they intend to be inattentive about other people's emotions and rights. It seems natural that opiate addicts are lower in cooperativeness dimension. These people are intolerant, do not adhere to the principles and rules, and are inattentive to others' emotions and rights. 
The difference of nicotine addicts and ordinary population with opiate dependent individuals in this dimension relates to supportiveness, adherence to the rules and principles, participation in group works, compassion, kindness, and patience. This finding is in agreement with the findings of many previous studies such as those of Evren et al. (21) and Herrow et al. (22).

High novelty seeking and low cooperativeness in drug dependent people are two distinguished features. Evren et al. (21) argued that high novelty seeking is one of the distinguished features in category B of personality disorders, namely, the same category in which anti-social personality disorder is placed; therefore, drug dependent individuals with higher novelty seeking may have symptoms of anti-social personality disorder. Le Bon et al. (8) found that heroin abusers' (an opiate substance) personality profile indicate more anti-social personality traits compared to that of alcohol addicts. Evren et al. (21) also pointed out that reward dependence is one of the characteristics of category A, high reward novelty seeking is one of the characteristics of category B, and high harm avoidance is one of the characteristics related to category C of personality disorders (21).

Moreover, results showed that low onset age of smoking cigarettes, lower education, and low cooperativeness and self-directedness dimensions predicted future use of opiate drugs after onset of smoking cigarettes. In a research performed on the onset age of drug use, Chen et al. (23) identified that low onset age of smoking is one of the predisposing factors for future drug use. This implies that the lower the onset age of smoking, the more probable that the person refers to using other illegal drugs (23). Studies indicated that cigarettes can be the gateway drug for other substances including alcohol. Mayet et al. (12) reported that the average onset age of smoking in their research samples was 13.4 (13.3 for boys, 13.5 for girls), and the mean (average) onset age of using alcohol was 15.1 (15.0 for boys, 15.2 for girls). It implies the lower age mean in smokers. Experiencing tobacco before starting to use hashish occurred in $98 \%$ of hashish users (12). Guxens et al. (11) indicated that tobacco and alcohol use preceded the use of hashish and the performed meta-analyses showed that it is 1.7 to 2.6 times more likely that tobacco and alcohol consumers use hashish. Therefore, the current research results are in accordance with those of other studies, indicating that lower onset age of smoking is a predisposing factor for future use of other drugs. Also, it is natural that when self-directedness traits are cases such as responsibility, purposefulness, trouble-shooting, selfacceptance, and adapting to society's norms, then this dimension can play an effective role to predict drug dependence. Self-directedness is, to some extent, a component of a coherent ego that enables individuals to delay satisfying their needs, be self-accepted, purposeful, and responsible. Low cooperativeness dimension in the present research is another predicting factor of drug de- pendence. As mentioned in the previous sections, cases such as empathy, sympathy, usefulness, and having a clean heart are among cooperativeness traits. Therefore, cooperativeness can be another component of a coherent ego, it means that individuals can consider norms of the society, be socially useful, and have empathy and a clean heart. In general, three dimensions of self-directedness, cooperativeness, and self-transcendence can, to some extent, reflect an individual's coherent ego and degree of sophistication. Then, it can be explained that low character dimensions in opiate addicts, that were low in all three dimensions in this research, can indicate ego incoherence and non-sophistication.

Evren et al. (21) in their research concluded that high novelty seeking and low cooperativeness along with low onset age of smoking cigarettes predict drug dependence. In their study, subscales predicting drug dependence were more reasonable than low age, lower scores in subscales of sympathy and compassion vs. malice and usefulness, and higher scores in subscale of spiritual acceptance vs. materialism. Therefore, low self-directedness and cooperativeness, low onset age of smoking cigarettes and low education can predict drug dependence.

According to the current and prior studies, it is clarified that many of the people using illegal substances have some personality characteristics such as novelty seeking, and antisocial traits that cause to start smoking in lower ages, and then approach to use any kind of substances. This matter can help to conduct better therapies to treat substance abusers and dependents.

\section{Acknowledgments}

Authors wish to thank all opiate and nicotine abuse therapy clinics for their contribution to the study.

\section{Footnotes}

Authors' Contribution:Bahareh Amirabadi developed the idea and conducted main procedure of study and integrated all previous studies with this study; Mohammad Nikbakht conducted all collecting and analyzing data; Neda Alibeygi directed all procedures in this study; Mostafa Nokani and Hadi Safari helped with the conduction of study.

Funding/Support:The current study was financially supported by Shahid Beheshti University of Medical Sciences, Tehran, IR Iran.

\section{References}

1. Sadock BJ, Sadock VA, Ruiz P. Comprehensive Textbook of Psychiatry. 9th ed. New York: Lippincott Williams \& Wilkins; 2009. pp. 875-6.

2. Kring A, Davison GC, Neale JM. Abnormal Psychology. 1st ed. Tehran: Arjmand; 2009

3. Verheul R. Co-morbidity of personality disorders in individuals with substance use disorders. Eur Psychiatry. 2001;16(5):274-82. [PubMed: 11514129]

4. Craig RJ. Prevalence of Personality Disorders among Cocaine and Heroin Addicts. Subst Abus. 2000;21(2):87-94. doi: 10.1080/08897070009511421. [PubMed: 12466649] 
5. Compton WM, Conway KP, Stinson FS, Colliver JD, Grant BF. Prevalence, correlates, and comorbidity of DSM-IV antisocial personality syndromes and alcohol and specific drug use disorders in the United States: results from the national epidemiologic survey on alcohol and related conditions. J Clin Psychiatry. 2005;66(6):67785. [PubMed: 15960559]

6. Grant BF, Stinson FS, Dawson DA, Chou SP, Ruan WJ, Pickering RP. Co-occurrence of 12-month alcohol and drug use disorders and personality disorders in the United States: results from the National Epidemiologic Survey on Alcohol and Related Conditions. Arch Gen Psychiatry. 2004;61(4):361-8. doi: 10.1001/archpsyc.61.4.361. [PubMed:15066894]

7. Franques $\mathrm{P}$, Auriacombe M, Tignol J. [Addiction and personality] Encephale. 2000;26(1):68-78. [PubMed:10875064]

8. Le Bon O, Basiaux P, Streel E, Tecco J, Hanak C, Hansenne M, et al. Personality profile and drug of choice; a multivariate analysis using Cloninger's TCI on heroin addicts, alcoholics, and a random population group. Drug Alcohol Depend. 2004;73(2):175-82. [PubMed: 14725957]

9. Sartor CE, Xian H, Scherrer JF, Lynskey MT, Duncan AE, Haber $\mathrm{JR}$, et al. Psychiatric and familial predictors of transition times between smoking stages: results from an offspring-oftwins study. Addict Behav. 2008;33(2):235-51. doi: 10.1016/j.addbeh.2007.09.002. [PubMed: 17900819]

10. Kandel DB, Davies M. High school students who use crack and other drugs. Arch Gen Psychiatry. 1996;53(1):71-80. [PubMed: 8540779]

11. Guxens M, Nebot M, Ariza C, Ochoa D. Factors associated with the onset of cannabis use: a systematic review of cohort studies. Gac Sanit. 2007;21(3):252-60. [PubMed:17565903]

12. Mayet A, Legleye S, Chau N, Falissard B. The mediation role of licit drugs in the influence of socializing on cannabis use among adolescents: A quantitative approach. Addict Behav. 2010;35(10):8905. doi:10.1016/j.addbeh.2010.06.001. [PubMed: 20584572]

13. Dzamonja-Ignjatovic T, Svrakic DM, Svrakic N, Jovanovic MD, Cloninger RC. Cross-cultural validation of the revised Temperament and Character Inventory: Serbian data. Compr Psychiatry. 2010;51(6):649-55. doi: 10.1016/j.comppsych.2009.09.009. [PubMed: 20965312]
14. Ayati MM. Dimensional Structure of Major Depression Period Symptoms and It's Relationship with Temperament and Character. Tehran University; 2011.

15. Ebbert JO, Patten CA, Schroeder DR. The Fagerstrom Test for Nicotine Dependence-Smokeless Tobacco (FTND-ST). Addict Behav. 2006;31(9):1716-21. doi: 10.1016/j.addbeh.2005.12.015. [PubMed: 16448783]

16. Shams J, Azizi A, Mirzaei A. Correlation between Distress Tolerance and Emotional Regulation With Students Smoking Dependence. Hakim Res J. 2010;13(1):11-8.

17. Marsden J, Gossop M, Stewart D, Best D, Farrell M, Lehmann P, et al. The Maudsley Addiction Profile (MAP): a brief instrument for assessing treatment outcome. Addiction. 1998;93(12):1857-67. [PubMed: 9926574]

18. Mathias R. Novelty Seekers and Drug Abusers Tap Same Brain Reward System, Animal Studies Show. Prev Res NIDA. 2010;10(4):28496.

19. Ball SA, Kranzler HR, Tennen H, Poling JC, Rounsaville BJ. Personality disorder and dimension differences between type A and type B substance abusers. J Pers Disord. 1998;12(1):1-12. [PubMed: 9573515]

20. Gabel S, Stallings MC, Schmitz S, Young SE, Fulker DW. Personality dimensions and substance misuse: relationships in adolescents, mothers and fathers. Am J Addict. 1999;8(2):101-13. [PubMed: 10365190]

21. Evren C, Evren B, Yancar C, Erkiran M. Temperament and character model of personality profile of alcohol-and drug-dependent inpatients. Compr Psychiatry. 2007;48(3):283-8. doi: 10.1016/j. comppsych.2006.11.003. [PubMed:17445524]

22. Herrero MJ, Domingo-Salvany A, Torrens M, Brugal MT, Gutierrez F. Personality profile in young current regular users of cocaine. Subst Use Misuse. 2008;43(10):1378-94. doi: 10.1080/10826080801922652. [PubMed:18696374]

23. Chen X, Unger JB, Palmer P, Weiner MD, Johnson CA, Wong MM, et al. Prior cigarette smoking initiation predicting current alcohol use: evidence for a gateway drug effect among California adolescents from eleven ethnic groups. Addict Behav. 2002;27(5):799817. [PubMed: 12201385$]$ 